Geopolítica(s) Revista de estudios sobre espacio y poder ISSN: 2172-3958

\title{
Hegemonía y desarrollo rural: análisis territorial de políticas de desarrollo rural en Benito Juárez (Buenos Aires, Argentina)
}

\author{
Fernando González ${ }^{1}$
}

Recibido: 19 de enero de 2017 / Aceptado: 21 de agosto de 2017

Resumen. En las últimas décadas ha tomado relevancia la dimensión territorial del desarrollo rural. En este marco surgen instituciones estatales y mecanismos dirigidos a obtener y organizar consensos en los diferentes niveles de aplicación de las políticas (regional, nacional, provincial y local). Se promueve la idea del territorio como un ámbito de unión entre múltiples agentes públicos y privados. Partiendo de que el mismo debe ser concebido como un ámbito de ejercicio del poder, analizamos las políticas públicas como un proceso de construcción de hegemonía. Para ello, partiendo de las diferentes contribuciones de la geografía crítica y de otras disciplinas de las ciencias sociales, analizamos el surgimiento de las políticas para la agricultura familiar (AF) como elemento novedoso del desarrollo rural en Argentina - $\mathrm{y}$ en la región-. Lo hacemos con base en un estudio de caso en el partido de Benito Juárez (Provincia de Buenos Aires) donde realizamos una investigación cualitativa con base en trabajos de campo y entrevistas a informantes calificados. Las conclusiones a las que llegamos ponen de relieve cómo los mecanismos de inclusión (económica y/o política) buscan producir nuevos sujetos, acordes a las necesidades de los actores hegemónicos.

Palabras clave: territorio; territorialidad; hegemonía; agricultura familiar; políticas públicas.

\section{[en] Hegemony and Rural Development: A Territorial Analysis of Rural Development Policies in Benito Juárez (Buenos Aires, Argentina)}

\footnotetext{
Abstract. In recent years, studies of rural development have focused on the territorial dimension, with state institutions and mechanisms aimed to obtain and organize consensuses on the different policy levels (regional, national, provincial and local) promoting the idea that the territory shall be the area of interaction between public and private agents, as well as the reference point for the exercise of power. The current article seeks to analyze public policies under the premise that these constitute themselves as processes of hegemony construction. Building on contributions from critical geography and other disciplines in the social sciences, we address the emergence of family agriculture (FA) policies as a novel element of rural development in Argentina -and the region. Our insights are drawn from a case study conducted in the Benito Juárez partido (Buenos Aires province). The investigation is based on fieldwork and interviews with key informants. It will be concluded that the economic and/or political inclusion mechanisms put in place set out to produce new subjects, consonant with the necessities of hegemonic actors.

Keywords: territory; territoriality; hegemony; family agriculture; public policies.

1 Consejo Nacional de Investigaciones Científicas y Técnicas (CONICET - Becario Posdoctoral). Universidad de Buenos Aires (UBA), Facultad de Filosofía y Letras, Instituto de Geografía "Dr. Romualdo Ardissone", Programa de Estudios Regionales y Territoriales, Buenos Aires (Argentina).

E-mail: gonzalezjosefer@gmail.com
} 


\title{
[pt] Hegemonia e desenvolvimento rural: Análise territorial de políticas de desenvolvimento rural em Benito Juárez (Buenos Aires, Argentina)
}

\begin{abstract}
Resumo. Nas últimas décadas a dimensão territorial do desenvolvimento rural tem ganho relevância. Nesse contexto surgem instituições estatais e mecanismos visando a obter e organizar consensos nos diferentes níveis de aplicação das políticas (regional, nacional, provincial e local). Promove-se a ideia do território como âmbito de união entre múltiplos agentes públicos e privados. Partindo da premissa de que o território deve ser concebido como âmbito de exercício do poder, analisamos as políticas públicas como um processo de construção de hegemonia. Para tanto, partindo das diferentes contribuições da geografia crítica e de outras disciplinas das ciências sociais, analisamos o surgimento das políticas para a agricultura familiar (AF) como elemento inovador do desenvolvimento rural na Argentina - e na região. Nossa análise se fundamenta em estudo de caso em Benito Juárez (Província de Buenos Aires) onde realizamos uma pesquisa qualitativa com base em trabalhos de campo e entrevistas junto a informantes qualificados. As conclusões a que chegamos enfatizam como os mecanismos de inclusão (econômica e/ou política) buscam produzir novos sujeitos, de acordo com as necessidades dos atores hegemônicos.
\end{abstract}

Palavras-chave: território; territorialidade; hegemonia; agricultura familiar; políticas públicas.

Sumario. Introducción. 1. Perspectiva teórica. 2. Políticas que organizan el consenso. 3. Detrás de las políticas: territorialidades en pugna en Benito Juárez. Reflexiones finales. Bibliografía.

Cómo citar: González, Fernando (2017) "Hegemonía y desarrollo rural: análisis territorial de políticas de desarrollo rural en Benito Juárez (Buenos Aires, Argentina)". Geopolitica(s). Revista de estudios sobre espacio y poder, vol. 8, núm. 2, 203-223.

El concepto de hegemonía, introducido por Gramsci con el fin de anticipar el papel de la clase obrera en la construcción de una nueva sociedad, permite analizar la acción de la burguesía, en particular en todo lo relativo al espacio.

Henri Lefebvre (2013 [1974]:

La producción social del espacio

\section{Introducción}

En las últimas décadas, tanto en el marco de los estudios rurales provenientes de las ciencias sociales como en el ámbito de las políticas públicas, se ha comenzado a problematizar la dimensión territorial del desarrollo rural. Una de las versiones más difundidas de este paradigma es el desarrollo territorial rural (DTR), que plantea el territorio como "una construcción social, es decir, un conjunto de relaciones sociales que dan origen y a la vez expresan una identidad y un sentido de propósito compartidos por múltiples agentes públicos y privados" (Schejtman \& Berdegué, 2004: 5). En este marco, surgen instituciones estatales y diferentes mecanismos dirigidos a obtener y organizar el consenso en los diferentes niveles de aplicación de las políticas (regional, nacional, provincial y local).

A lo largo de este trabajo analizaremos el surgimiento de las políticas para el desarrollo rural - focalizadas hacia el sector de la agricultura familiar - como un 
proceso de construcción de hegemonía, es decir, de un ejercicio del poder basado en el consenso de los gobernados. Ello nos brinda elementos para el análisis de la producción social del espacio y el territorio a partir de relaciones de poder y de sus diferentes dimensiones (económicas, políticas, ideológicas).

Para ello comenzamos este trabajo exponiendo los principales elementos teóricos con los cuales abordaremos el debate en torno al territorio y al poder, considerado éste desde la óptica gramsciana de la hegemonía. Tomaremos para eso diferentes aportes de la geografía crítica y de otras disciplinas de las ciencias sociales que nos permiten reforzar el análisis. En segundo lugar, analizaremos el surgimiento de las políticas para la agricultura familiar (AF), y cómo ellas son construidas a partir de mecanismos de construcción de consensos en todos sus niveles, cobrando notoriedad la orientación de los consensos por parte de actores que devienen hegemónicos. Por último, analizaremos cómo se produce el territorio en la implementación a nivel local de algunos elementos provenientes de estas políticas públicas. Lo haremos con base en un estudio de caso, dentro del partido bonaerense de Benito Juárez, donde hemos desarrollado un trabajo de campo con abordaje cualitativo, centrado principalmente en entrevistas a informantes calificados y complementado con información secundaria.

Las conclusiones a las que llegamos en este artículo buscan simplemente poner de relevancia la pertinencia de algunos elementos del enfoque gramsciano de la hegemonía para el análisis territorial, realizando un aporte original al estado de la cuestión en los estudios rurales, visualizando las formas por las cuales diferentes actores logran convertir en universales sus particulares visiones sobre los modelos de desarrollo rural.

\section{Perspectiva teórica}

Luego de los intentos de planificación del desarrollo nacional y regional promovidos por la Alianza para el Progreso (1961-1970), los estudios sobre el espacio y su inserción en la política pública fueron desapareciendo de la política pública. Sin embargo, bajo diferentes denominaciones (desarrollo endógeno, local, rural, territorial, etc.) resurgió el interés por el territorio en la década de 1990. Este renacimiento "se centró en la identificación de territorios con condiciones de "atractividad» para captar el capital y las inversiones foráneas" (Manzanal, 2007: 30). Diferentes ideas y conceptos se asocian a estas propuestas: descentralización, concertación público-privada y, fundamentalmente, la necesidad de encontrar consensos entre todos los actores.

Estos encuadres manifiestan una determinada "visión de mundo" sobre lo que deben ser los territorios. Se busca potenciar aspectos como la competencia entre territorios o la innovación territorial. En este marco, como sostiene Mabel Manzanal "para ser territorios hay que mostrar potencialidad para un desarrollo endógeno, a través de sinergias originadas en recursos, competencias, innovación" (2007: 31). Fuera de esas capacidades no existe el territorio en muchas de estas propuestas.

Para el caso de Latinoamérica y en torno a la cuestión rural, el ejemplo más cabal de estas nociones, lo constituye el enfoque del Desarrollo Territorial Rural (DTR). Diferentes instituciones como la Organización de las Naciones Unida para la Alimentación y la Agricultura (FAO) a través de sus instituciones regionales di- 
funden este corpus teórico. Según Alexander Schejtman y Julio Berdegué (2004: 45) — dos de sus principales exponentes - el DTR sostiene que los territorios rurales se desarrollan en la medida que se insertan en mercados dinámicos, "uniendo a sus propios actores, superando las disputas y articulando con otros actores y territorios, rurales y/o urbanos" (Manzanal, 2007: 32). En este sentido, se ignora e invisibiliza la estructura de poder que es la que da sentido y configura los territorios, cayendo en una "fetichización del territorio" (Ramírez Miranda, 2011). Aportando a esta visión crítica, sostenemos que para comprender el territorio - y actuar en él-, es preciso revelar el poder que dichas políticas ocultan.

Es por ello que sostenemos, en primer lugar, que "espacio y territorio deben ser tratados como concepciones distintas" (Haesbaert, 2010: 164). Partiendo de ello, afirmamos que "el territorio se forma a partir del espacio, y es resultado de una acción conducida por un actor sintagmático (un actor que realiza un programa) en cualquier nivel. Al apropiarse de un espacio, concreta o abstractamente, el actor «territorializa» el espacio" (Raffestin 1993: 143). Por lo tanto, la producción social del espacio es solo la base del territorio. El concepto de territorio va más allá y pretende enfatizar la dimensión política de dicha producción social.

Entonces, para visualizar mejor al territorio en tanto "resultado de una acción", tomamos el concepto de territorialidad, definida como "el intento de un individuo o grupo de afectar; influir o controlar gente, elementos y sus relaciones delimitando y ejerciendo un control sobre un área geográfica" (Sack, 1986: 17). Pero ¿en qué sentido se busca influir? ¿de qué maneras? ¿en qué aspectos de la vida social? Robert Sack sostiene que a pesar de ser central la perspectiva política de la territorialidad existen también aspectos económicos y culturales. Estas diferentes expresiones están "íntimamente ligada al modo como las personas utilizan la tierra, como ellas mismas se organizan en el espacio y como ellas dan significado al lugar" (Sack, 1986, citado en Haesbaert, 2006: 86). En síntesis, como sostiene Rogerio Haesbaert, "el territorio puede ser concebido a partir de la imbricación de múltiples relaciones de poder, del poder más material de las relaciones económico-políticas al poder más simbólico de las relaciones de orden más estrictamente cultural" (2006: 79).

Entonces nos surge la pregunta de hacia dónde puede llevarnos dicha afirmación ¿Cómo se despliegan esas "múltiples relaciones de poder"? ¿Qué es lo que las hace eficaces y duraderas? ¿Cómo es que el poder (en minúscula, como propone Raffestin) "aprovecha todas las fisuras sociales para infiltrarse hasta el corazón del hombre" (Raffestin, 1993: 52)? Estos interrogantes nos llevan al terreno de los estudios sobre el poder, para revelar los aspectos más ocultos del poder, que son los más efectivos.

Los antecedentes de las discusiones sobre el poder datan de los comienzos de la filosofía política donde el poder era resultado del "insaciable deseo humano por apropiarse del tiempo, el espacio y los objetos" (Duso, 2005: 31). Sin embargo, creemos que las ideas modernas sobre poder comienzan con los aportes de Max Weber, que en su libro Economía y Sociedad sostuvo que poder "significa la probabilidad de imponer la propia voluntad, dentro de una relación social, aun contra toda resistencia y cualquiera que sea el fundamento de esa probabilidad" (Weber, 2002 [1922]: 43). Pero como esta definición es "sociológicamente amorfa", propone diferenciar a éste de la dominación, entendida como: 
[U]n estado de cosas por el cual una voluntad manifiesta ("mandato") del "dominador" influye sobre los actos de otros (del "dominado"), de tal suerte que en un grado socialmente relevante estos actos tienen lugar como si los dominados hubieran adoptado por sí mismos y como máxima de su obrar el contenido del mandato (“obediencia") (Weber, 2002 [1922]: 699).

A partir de estas dos definiciones, es abundante la bibliografía existente al respecto y pueden observarse varias "bifurcaciones". Siguiendo a Norberto Bobbio (1985) podemos hablar de tres corrientes de interpretación del poder: sustancialista, subjetivista y relacional. Para la teoría sustancialista el poder se da por los medios con los que cada uno cuenta para lograr la voluntad de los otros (objetos, dinero, fuerza, etc.). En este sentido el poder es algo que se posee (una cosa). La teoría subjetivista, explica el poder como un factor exógeno, el poder es otorgado a una persona o grupo de personas. Cobran fuerza en estas teorías los procesos de legitimación. Por último, la teoría relacional explica que el poder se debe entender como "una relación entre dos sujetos de los cuales el primero obtiene del segundo un comportamiento que éste de otra manera no habría realizado" (Bobbio, 1985: 104).

Podemos decir que la vasta mayoría de las concepciones utilizadas en la geografía crítica parten de considerarlo como un fenómeno relacional, como bien sostiene Raffestin en su obra Geografía del Poder, al decir que "poder se manifiesta por ocasión de una relación. [...] [Es un proceso] de intercambio o de comunicación cuando, en la relación que se establece, los dos polos se confrontan" (1993: 53). Desde estas perspectivas se busca abordar el aspecto productivo y no sólo represivo del poder. En ese sentido pudiendo adoptar una perspectiva foucaltiana — como la adoptada por Raffestin-, hemos optado por otra concepción, la gramsciana, ya que creemos que es más útil para analizar fenómenos vinculados a políticas públicas, donde el Estado ocupa un rol determinante.

Creemos que la concepción de "hegemonía" formulada por Antonio Gramsci ha construido un sistema más claramente tricotómico, poniendo en una justa tensión los elementos político, económico e ideológico del poder. Si bien podemos ver diferentes ópticas y enfoques en torno a esta noción, creemos que puede sintetizarse en aquel momento en que un grupo decide:

[C]rear las condiciones favorables para la máxima expansión del mismo grupo; pero este desarrollo y esta expansión son concebidos y presentados como la fuerza motriz de una expansión universal, de un desarrollo de todas las energías "nacionales". El grupo dominante es coordinado concretamente con los intereses generales de los grupos subordinados y la vida estatal es concebida como una formación y superación continua de equilibrios inestables (en el ámbito de la ley) entre los intereses del grupo fundamental y los de los grupos subordinados, equilibrios en donde los intereses del grupo dominante prevalecen hasta cierto punto, o sea, hasta el punto en que chocan con el mezquino interés económico-corporativo (Gramsci, 1980: 58).

Este es el momento en que una clase decide además de dominar, dirigir a la sociedad. Dirigirla significa también construirla, educarla, "elevar a la gran masa de la población a un determinado nivel cultural y moral” (Gramsci, 1980: 154). Así se traza la diferencia entre clase dominante y dirigente. Clase dominante es la "deten- 
tadora de la mera fuerza coactiva", en cambio dirigente es la que gobierna "con el consenso de los gobernados, pero con un consenso organizado". La primera situación es una dictadura, en cambio la segunda es la situación de un régimen de gobierno con hegemonía. Para ello, la clase dirigente "pide el consenso, pero también lo «educa» por medio de las asociaciones políticas" (Gramsci, 1980: 155).

A diferencia de varias miradas relacionales del poder, que dejan en un segundo plano el rol del Estado, el planteo gramsciano supone poner en el centro del análisis al Estado, donde se desarrolla "un gran despliegue organizativo y de hombres, de largo aliento, con el fin de desarticular las «trincheras» enemigas" (Thwaites Rey, 1994: 12). Este papel les cabe a los llamados "intelectuales orgánicos", encargados de organizar el "consentimiento espontáneo" de las grandes masas de población a las decisiones de la clase dirigente y gestionar el aparato de coerción estatal que asegura "legalmente" la obediencia a las decisiones de la clase dirigente (Gramsci, 1980: 394-395). Estos actores tienen un rol central en la construcción de la hegemonía.

Al intentar operativizar y desagregar diferentes componentes de la hegemonía, vemos que, las dimensiones propuestas por diferentes geógrafos (Haesbaert, 2006; Sosa Velázquez, 2012; y otros) en el análisis del territorio también pueden ser utilizadas. Tan es así que proponemos pensar en tres dimensiones de la hegemonía: económica, política e ideológica (simbólica, cultural). Al mismo tiempo, esta proposición teórica se diferencia de la visión del poder que propone Raffestin, que sostiene que es "inútil distinguir un poder político, económico, cultural etc." (Raffestin, 1993: 53), aunque más no sea como una necesidad analítica.

Una de las afirmaciones que dan pie a pensar en una dimensión económica es que "la hegemonía presupone indudablemente que se tienen en cuenta los intereses de los grupos sobre los cuales se ejerce la hegemonía [...], ya que si la hegemonía es ético-política no puede dejar de ser también económica" (Gramsci, 1980: 4041). Éste tal vez sea una de los aspectos menos tratados en la literatura sobre hegemonía, sin embargo, otros autores han reforzado este enfoque visibilizando cómo la clase dirigente debe hacer avanzar a la sociedad en su conjunto hacia adelante, asegurando "la «incorporación» de los estratos populares al desarrollo económicosocial" (Thwaites Rey, 1994). Bajo esta dimensión podemos analizar las diferentes acciones del Estado y de actores que buscan posicionarse como hegemónicos, en las que buscan incluir a los sectores subalternos mediante diferentes iniciativas de tipo económicas: programas asistenciales, de inclusión social, de generación de empleos o de subsidios; iniciativas para mejorar las capacidades productivas de agricultores familiares; programas de ampliación del consumo popular, y todos aquellos que mejoren la percepción de rentas son fundamentalmente los que serán objeto de análisis en esta dimensión, profundizada en artículos previos (González, 2016).

En segundo lugar, analizar una dimensión política nos lleva a pensar en cómo las clases dominantes se transforman en dirigentes a nivel político en torno al Estado. Para ello llevan a cabo una operación de "revolución pasiva". Esto es "un proceso de transformación «desde lo alto» en el que se recupera una parte de las demandas «de abajo», pero quitándoles toda iniciativa política autónoma [...] lo cual genera consenso, sin dar poder político" (Balsa, 2006: 27). En este proceso ocurre "una combinación - desigual y dialéctica - de dos tensiones, tendencias o momentos: restauración y renovación, preservación y transformación” (Modonesi, 
2012: 141). Otra forma en la que buscan conservar su posición dirigente y al mismo tiempo incorporar a los sectores subalternos, es mediante el denominado "transformismo", por el cual "la clase dominante integra a los intelectuales de otros grupos sociales decapitando así su dirección política e ideológica" (Portelli, 1977: 75). En esta dimensión cobran importancia las formas a través de las cuales se internalizan las demandas subalternas y, por lo tanto, cómo son institucionalizadas. También el papel que desempeñan los "intelectuales orgánicos" y por lo tanto las discusiones sobre la "mediación social" abundante en los estudios rurales, pero poco integrada a la discusión sobre la construcción de la hegemonía.

Las dos dimensiones nombradas, no actúan de manera independiente entre sí, sino que son amalgamadas por un cúmulo de representaciones y pensamientos mediante los cuales una clase - o fracción de clase o grupo de interés - presenta sus propios intereses como los de un conjunto más amplio o de toda la sociedad. Llamamos a este conjunto de ideas la dimensión ideológica. Si bien, adherimos a la propuesta de que el poder circula en múltiples direcciones, la hegemonía tiene su centro de irradiación desde el Estado. Y es en ese sentido que Gramsci sostiene que "cada Estado es ético en cuanto una de sus funciones más importantes es la de elevar a la gran masa de la población a un determinado nivel cultural y moral, nivel que corresponde a las necesidades de desarrollo de las fuerzas productivas y, por consiguiente, a los intereses de las clases dominantes" (1980: 154). Es en esta misma dirección que el geógrafo Richard Peet, plantea la existencia de "centros de poder", un "agrupamiento de instituciones interconectadas, o lo que podría ser llamado un complejo institucional" (Peet, 2007: 31). Ellos pueden ser clasificados como hegemónicos ya que "producen ideas y políticas con suficiente profundidad teórica y apoyo financiero para dominar el pensamiento vastos campos de poder" (Peet, 2007: 32).

Desde estos centros surgen diferentes elementos que dan sustento a esta dimensión: se construyen "identidades colectivas" con las que los grupos sociales son identificados (como sucede con la categoría de "agricultura familiar"), se asignan roles a los diferentes actores, metas y objetivos a los diferentes colectivos sociales (ser los garantes de la seguridad alimentaria). Nos referimos a "comportamientos prescritos para quienes ocupan posiciones sociales particulares", los cuales son portadores de un repertorio cultural específico que los legitima o deslegitima en su accionar (Portes, 2006: 20).

Sintetizando, partimos del territorio como la imbricación de múltiples relaciones de poder (Haesbaert, 2006), que es resultado de los intentos "de un individuo o grupo de afectar, influir o controlar gente, elementos y sus relaciones" (Sack, 1986: 17), es decir de las territorialidades. Este proceso, es de un "equilibrio inestable", resultante de procesos de negociaciones entre diferentes actores. Como afirma Saquet el territorio es delimitado por prácticas espaciales que pueden "no ocurrir de manera precisa, pueden ser irregular y cambiar históricamente, o bien suceder una diversificación de las relaciones sociales en un juego de poder cada vez más complejo" (Saquet, 2007: 31). Sin embargo, no es un juego de suma cero. Una fuerza se debe imponer. Por ello Sack plantea que la territorialidad que vence "envuelve las perspectivas de aquellos controlados y de aquellos que ejecutan el control, sean ellos individuos o grupos" (Sack, 2013: 80). Analizar la composición de esa territorialidad-síntesis, es central para nuestro análisis. 
En las dinámicas que se establecen en los diferentes niveles de implementación de las políticas públicas para el desarrollo rural en Argentina, podemos ver cómo este proceso se despliega. A nivel local las políticas modifican y/o refuerzan determinadas relaciones de poder y territorialidades, produciendo transformaciones territoriales. Creemos que esta perspectiva de análisis permite agudizar la mirada sobre las relaciones de poder, que luego articulan proyectos de hegemonía social y que se materializan en el espacio, produciendo el territorio. De esta manera buscamos contribuir a lo iniciado por muchos autores que buscan "llevar esta discusión a una arena relativamente inexplorada en la literatura sobre la hegemonía [...]: la producción de lugares" (Gordillo, 2006: 196). Ya que "la hegemonía configura el tipo de lugares por los que la gente considera que vale la pena luchar. Ello también significa examinar cómo la hegemonía contribuye a producir lugares como arenas políticas inestables" (Gordillo, 2006: 198).

Cuadro 1. Síntesis de la propuesta conceptual para el análisis

\begin{tabular}{|c|c|c|c|}
\hline Poder & Hegemonía & Territorialidad & Territorio \\
\hline Es una relación social & $\begin{array}{l}\text { Se manifiesta como un } \\
\text { proceso }\end{array}$ & $\begin{array}{l}\text { Influencia sobre un área (y } \\
\text { sus elementos) }\end{array}$ & $\begin{array}{l}\text { Resultado de las diferen- } \\
\text { tes territorialidades }\end{array}$ \\
\hline Económico-material & $\begin{array}{l}\text { Incluir dentro del desarro- } \\
\text { 1lo económico a los secto- } \\
\text { res subalternos }\end{array}$ & $\begin{array}{l}\text { Acciones y políticas sobre } \\
\text { inclusión social, económica } \\
\text { y/o productiva }\end{array}$ & \multirow{3}{*}{$\begin{array}{l}\text { La territorialidad hege- } \\
\text { mónica envuelve a las } \\
\text { subalternas (o algunos de } \\
\text { sus elementos), en un } \\
\text { equilibrio inestable que le } \\
\text { otorga su propio dina- } \\
\text { mismo y posibilidades de } \\
\text { transformación }\end{array}$} \\
\hline Político-institucional & $\begin{array}{l}\text { Se incorporan demandas y } \\
\text { dirigentes, sin iniciativa } \\
\text { subalterna }\end{array}$ & $\begin{array}{l}\text { Negociación, consenso, en- } \\
\text { frentamiento (autonomía y } \\
\text { subordinación) }\end{array}$ & \\
\hline Ideológico-cultural & $\begin{array}{l}\text { Elevar el nivel cultural y } \\
\text { moral (según intereses de } \\
\text { clases dominantes) }\end{array}$ & $\begin{array}{l}\text { Valores, ideas, identidades, } \\
\text { roles de los distintos acto- } \\
\text { res y de sus prácticas }\end{array}$ & \\
\hline
\end{tabular}

Fuente: Elaboración propia.

\section{Políticas que organizan el consenso}

Analizar la construcción de hegemonía y territorio desde la óptica propuesta, requiere clarificar cómo concebimos a la política pública, principal instrumento estatal del desarrollo rural. Siendo parte de un proceso social más amplio, en el que distintas demandas sociales se transforman en "cuestiones socialmente problematizadas", entendemos a la política pública "como un conjunto de acciones y omisiones que manifiestan una determinada modalidad de intervención [de las instituciones estatales] en relación con una cuestión que concita la atención, interés o movilización de otros actores en la sociedad civil" (Oszlak \& O'Donnel, 1995: 112 , el agregado es nuestro) ${ }^{2}$.

2 Partimos de que "ninguna sociedad posee la capacidad ni los recursos para atender la lista de necesidades y demandas de sus integrantes. Sólo algunas son «problematizadas», en el sentido de que ciertas clases, fracciones de clase, organizaciones [...] creen que puede y debe hacerse «algo» a su respecto y están en condiciones de promover su incorporación a la agenda de problemas socialmente vigentes. Llamamos «cuestiones» a estos asuntos (necesidades, demandas) «socialmente problematizados»» (Oszlak, 1982: 110). 
El proceso más amplio del que emergen las diferentes propuestas de desarrollo rural para el país y la región, es parte de una historia acumulada de propuestas estatales. El desarrollo rural no se instala en la agenda pública nacional desde un Estado de bienestar preocupado por la búsqueda de equidad, sino en "un modelo que minimiza el rol del Estado en la sociedad [...] y propone programas asistenciales y compensatorios para quienes se encuentran fatalmente condenados a la exclusión" (Lattuada et al., 2015: 73-74). Así, durante los años 1980 su accionar se circunscribe a la pobreza rural con el centro de atención puesto en los "minifundistas". Luego, con los programas de ajuste estructural de la década de 1990 en marcha, se impulsaron diferentes políticas de desarrollo rural-local para "pequeños productores", "pobre rural" o "productor de subsistencia", cada una focalizada según la situación del sector y de la región donde se implemente.

Fue en la primera década del nuevo siglo que apareció la idea de que el desarrollo debía ser territorial. Esto quería decir que "el ámbito de acción de la propuesta va más allá del espacio agrícola", buscando "ir más allá de la focalización de las iniciativas en las familias rurales pobres e incorporar o convocar a los distintos agentes que tienen presencia relevante" en el territorio en cuestión. Se busca también "la incorporación de los vínculos urbano-rurales en la definición del espacio de acción relevante", y otros elementos que le quitan peso a lo agrario dentro de la definición del problema territorial-rural (Schejtman \& Berdegué, 2004: 30). En este marco, es que se sostiene que el desarrollo territorial-rural (DTR) es:

Un proceso de transformación productiva e institucional de un espacio rural determinado. [...] La transformación productiva tiene el propósito de articular competitiva y sustentablemente a la economía del territorio con mercados dinámicos, lo que supone cambios en los patrones de empleo y producción de un espacio rural determinado. El desarrollo institucional tiene como objetivo estimular la concertación de los actores locales entre sí y entre ellos y los agentes externos relevantes, así como modificar las reglas formales e informales que reproducen la exclusión (Schejtman \& Berdegué, 2004: 30).

Bajo este paradigma, la referencia a los beneficiarios del desarrollo rural, pasa a ser "agricultor familiar". De la misma manera que el desarrollo ahora tiene que escapar a los límites de lo rural, los sujetos deben ser definidos también de acorde a esos objetivos. De ahí que la agricultura familiar es concebida de manera tan ambigua. En el caso argentino eso se puede ver en la definición de "agricultura familiar", donde estos actores pueden realizar la actividad siendo "propietarios de la totalidad o de parte de los medios de producción"; estando "cubiertos principalmente por la mano de obra familiar y/o con aportes complementarios de asalariados"; residiendo "en el campo o en la localidad más próxima a él"; y teniendo "como ingreso económico principal" — pero no el único — la actividad agropecuaria familiar (Ley $\mathrm{N}^{\mathrm{o}} 27.118$, art. 5).

Ambas definiciones, son impulsadas desde "centros de poder" (Peet, 2007) compuestos por diferentes instituciones vinculadas históricamente al desarrollo rural. Tomamos como epicentro de ese entramado institucional a la Reunión Especializada de Agricultura Familiar (REAF) del Mercosur. En ella jugaron un rol importante diferentes actores, que podemos caracterizar como "intelectuales orgánicos", ya que son en su mayoría "«gestores» del grupo dominante para el ejercicio de las 
funciones subalternas de la hegemonía social y del gobierno político" (Gramsci, 1980: 394). Son técnicos del Fondo Internacional de Desarrollo Agrícola (FIDA), los miembros de la Confederación de Organizaciones de Productores Familiares del MERCOSUR (COPROFAM) y funcionarios de los Estados parte del Mercosur. Es necesario resaltar, en lo referente a nuestra investigación que los tres están sumamente relacionados, ya que, en tanto que integrantes del FIDA, son al mismo tiempo miembros de las organizaciones que componen COPROFAM y de los programas para el sector en los países del MERCOSUR ${ }^{3}$.

Estos actores se encargan de difundir un ideario a través de las políticas para la agricultura familiar, donde los presupuestos del DTR entran en permanente tensión con las visiones de mundo propias de los sectores más empobrecidos del sector al que se dirigen dichas políticas. Para visualizar esto, primero ahondaremos en los aspectos políticos y económicos de las políticas, para luego analizar los componentes ideológicos con los que se busca "dirigir" el comportamiento de la agricultura familiar.

La dimensión política del desarrollo rural propuesto en Argentina tiene su epicentro en el proceso de institucionalización de la AF, que comienza en la REAF. En ese "centro de poder" se hacen inteligibles y operativas las diferentes definiciones y recomendaciones, que son aplicadas por las instituciones nacionales de desarrollo rural y luego implementadas a nivel provincial y local. Un primer elemento a considerar en este análisis son las formas en que se subordina políticamente a la agricultura familiar en estas instituciones. En el caso de la REAF, las definiciones centrales, se establecieron en reuniones donde sólo participaron integrantes de COPROFAM y luego se integró al espacio a diferentes organizaciones representativas de la heterogénea AF regional. Esto implica una posición subordinada para estas organizaciones en tanto participan de un espacio donde las normas centrales fueron previamente acordadas por los técnicos de FIDA, COPROFAM y de los Estados nacionales. Asimismo, la metodología de participación implica subordinación - a la vez que integración política- . Si bien las demandas de la agricultura familiar se integran y procesan a partir de la organización de Grupos Temáticos (GT), luego son evaluadas técnicamente por FIDA, y elevadas a niveles superiores. Es decir, la integración de la AF está en buena parte determinada por decisiones de actores que no forman parte de la $\mathrm{AF}$.

Luego, a partir de la incorporación de Argentina en la REAF, organizaciones de segundo y de tercer grado (provinciales y nacionales, respectivamente) comienzan a participar del proceso de institucionalización. En el año 2006, se crea el Foro Nacional de la AF (FoNAF) conformado por organizaciones del sector, pero bajo la órbita estatal. Se argumentaba que es función del Estado buscar el "consenso necesario para garantizar el crecimiento con integración social [...] [para lo cual] es conveniente contar con [...] la participación y el consenso de la agricultura familiar" (Res. SAGPyA 132/2006) ${ }^{4}$. Pero organizaciones del sector como el Movimiento Nacional Campesino Indígena (MNCI) denunciaron esta subordinación con respecto al Estado, al decir que "el foro expresa la «voz campesina», pero el mismo

\footnotetext{
Esto se puede observar en la composición del equipo de FIDA MERCOSUR, disponible en URL: $<$ http://fidamercosur.org/claeh/quienes-somos/equipo>, consultada el 12 de marzo de 2017.

4 Secretaría de Agricultura, Ganadería, Pesca y Alimentación (2006). Resolución 132/06. Creación del Foro Nacional de la Agricultura Familiar (FoNAF). Buenos Aires.
} 
está bajo control del Estado", y que "surge de acuerdos políticos entre la Federación Agraria (FAA) y sectores de la burocracia [...] para manejar mucho dinero de programas y relaciones con el Banco Mundial, el BID y el Estado" (MNCI, 2009). Es por ello, que muchas de las definiciones que va tomando el FoNAF se deben analizar atendiendo al rol que juegan los "intelectuales orgánicos" (de la FAA, de la SAGPyA y del FIDA), incluyendo en ello las diversas apreciaciones sobre el significado de la seguridad y la soberanía alimentaria (como sostuvimos en Manzanal \& González, 2010). También a ello refería una referente de la AF, que en una entrevista realizada sostuvo que al FoNAF "muchos intentaron transformarlo en organización de los productores, y, en realidad, un foro es un encuentro para discutir algo. Después vos pertenecés a una organización y yo a la otra" (Fernanda, referente de la AF, agosto 2012). Recién en 2011 esta organización obtiene una personería jurídica que la independiza del ámbito estatal y pasa a denominarse $\mathrm{Fe}$ deración de Organizaciones de la AF (FONAF, con mayúscula).

Algo similar sucedió en torno a la creación del Registro Nacional para la AF $(\text { ReNAF) })^{5}$. Sostiene Gabriela Schiavoni que esta institución "representa un compromiso entre estos dos modos de establecer equivalencias [...] Se lleva a cabo a partir de una innovación técnica: la medida resulta de la gestión asociada entre el Estado y las organizaciones sociales, nucleadas en el FoNAF" (2012: 52). Por lo tanto, representa una herramienta de inclusión. Sin embargo, como sostienen otros autores, "se registran principalmente a los productores beneficiarios de programas del Estado" (Paz \& Jara, 2014: 84). Como contracara, esto lo transforma en un instrumento de coerción para acceder a los beneficios de la política, ya que sin estar inscrito en él es imposible acceder a los programas para el sector.

En todo este proceso, pudimos visualizar una estrategia de incorporación de "intelectuales orgánicos" de la agricultura familiar en el Estado. Por ejemplo, miembros de la FAA luego ocuparon cargos en la SAGPyA. Del mismo modo, el MNCI - que había criticado esa subordinación frente al Estado- y también otras organizaciones, pasaron a formar parte importante de la gestión política para el sector ${ }^{6}$. Así, el propio Estado transforma a varios dirigentes de la AF en agentes estatales del gobierno. En este sentido, diferenciamos esta estrategia - denominada "transformismo", por Gramsci- de los planteamientos que hablan de una "cooptación" de las organizaciones sociales.

Si bien ésta es una práctica hegemónica mediante la cual los actores dominantes ven ampliadas sus bases de consenso y sustentación social y política, no podemos

5 El RENAF surge de los compromisos asumidos en la REAF por los Estados miembro. Todos los países se comprometieron a poner en funcionamiento "registros voluntarios" para el sector, donde poder visibilizar al sector, conocer su realidad y así tener elementos para la elaboración de políticas. Su carácter coercitivo estaba presente en su fundación ya que se instituyó como "el único medio por el cual los agricultores familiares podrán acceder a los beneficios de los instrumentos de políticas públicas diferenciales para su sector" (Res. SAGPyA 255/2007).

6 Miembros de la FAA ocuparon cargos en la SAGPyA, luego de iniciado el proceso de constitución de la REAF. Con el proceso de institucionalización de la AF más avanzado, referentes del MNCI ocuparon cargos en la "Dirección de apoyo a las organizaciones" (2012) y en la "Subsecretaría de Fortalecimiento Institucional de la SAF" (2014). El Movimiento Agrario de Misiones (MAM) la "Dirección Nacional de Identificación y Formalización de los agricultores familiares", la "Asamblea Campesina e Indígena del Norte Argentino" (ACINA) la de "Fortalecimiento y Apoyo a las Organizaciones de la AF", el Frente Nacional Campesino (FNC) la de "Programas y Proyectos para la AF", la de "Ferias Francas e intercambios regionales" fue ocupada por "Madre Tierra". 
desconocer que los actores subalternos ven en ella la posibilidad de constituirse en referentes sociales de carácter contrahegemónico o de mejorar su posición en las relaciones de fuerza. Interpretamos estos procesos dentro del carácter dialéctico de los procesos sociales donde el Estado es un campo de disputa de poder y de hegemonía. Ello significa que los nuevos actores incorporados al Estado podrían no ser interpretados exclusivamente como actores pasivos funcionales a la dominación, sino que también podrían ser sujetos activos en una "guerra de posiciones" - por seguir la denominación de Gramsci- dentro de la estructura estatal.

En los niveles provinciales y locales, la construcción del consenso también incluyó una nueva institucionalidad. Desde la Secretaría de Agricultura Familiar de la Nación (SAF) se desarrolló una política que implicó articular a las instituciones nacionales, provinciales y locales y a las organizaciones de la AF. Los encargados de esa articulación son los técnicos de extensión rural, quienes pasaron a ser considerados "agentes de desarrollo". Entre sus funciones debían "articular con instituciones [...], armar organizaciones, llevar a cabo los lineamientos de la SAF, agregado de valor, instalar los espacios de comercialización de los agricultores familiares, fortalecer las organizaciones que existen en el terreno" (Esteban, agente de desarrollo de la SAF, Octubre 2012). Lejos de sus funciones meramente técnicas, ahora son considerados actores políticos, "organizadores del consenso"7 . Entre ellos, algunos eran dirigentes de la AF. Así, se repetiría la estrategia transformista observada a nivel nacional, sin embargo, corresponde señalar que éstos fueron actores desarrollan acciones dirigidas a contrarrestar la subordinación que esa situación genera.

Vemos así que, en todos los niveles de elaboración e implementación de la política para la $\mathrm{AF}$, la construcción de consensos está en las manos de agentes estatales que actúan como "mediadores", tanto por parte del Estado nacional, como provincial y local. Son actores cuya función específica es "ser un organizador de masas, organizador de la «confianza»" (Gramsci, 1970: 2) de los agricultores familiares.

En definitiva, según cada coyuntura política local, cada relación de fuerzas, intereses en pugna, dicha política se acerca más o menos a los intereses de los agricultores familiares del ámbito espacial en cuestión. Conjuntamente se va conformando un territorio local más o menos afín a esos mismos intereses.

Analicemos ahora el aspecto económico de las políticas de desarrollo rural dirigidas a la AF. Buscan garantizar las "bases materiales del consenso" (Thwaites Rey, 2007), condición básica de la hegemonía; en nuestro caso, buscan incluir a los agricultores familiares tanto a nivel social, como económico y/o productivo. Pero, ¿de qué manera? Del análisis de las iniciativas surgidas de la REAF podemos hacer una evaluación de qué inclusión se propone. Una de ellas incluye recomendaciones para que el sector se inserte en las "cadenas de valor" (FAO/CEPAL/IICA, 2013) o en los "modelos de gobernanza de las cadenas agroindustriales" (Failde et al., 2011). Según consta en las actas de la institución, se busca insertar a la AF en los mercados globales. En 2005 se declaraba que la REAF buscaba la "inserción de las

La presencia de los "agentes de desarrollo" en la Provincia de Buenos Aires fue creciendo de manera notable en el período en el que realizamos la investigación. Mientras en el año 2009 eran 49, en 2012 eran más de 100 agentes. 
especificidades de la agricultura familiar en la Organización Mundial del Comercio" $"$.

A nivel local/regional, se busca "promover la inclusión social y económica de la $\mathrm{AF}$ en las cadenas productivas nacionales y regionales". Entre ellas adquiere un fuerte lugar la promoción de "compras estatales" para garantizar una venta más estable de la producción, asumiendo la "promoción social y económica del medio rural a través del [...] abastecimiento del mercado institucional de alimentos, por medio de las compras y adquisiciones gubernamentales"10. Otra recomendación es el "agregado de valor", con el que se inserta a los agricultores familiares de la región en las diferentes "cadenas de valor", vinculando de este modo con el sector industrial de cada cadena (actores con mayor poder económico y político que la $\mathrm{AF})$.

Luego se realizan acciones de "inclusión social" como el Monotributo Social Agropecuario, dirigido a productores informalizados. Es "la posibilidad de que, además de poder facturar su producción, pueda tener accesos a una obra social el productor, la familia, etc., para que pueda el día de mañana jubilarse" (Orlando, coordinador provincial de la SAF, Agosto 2012). Esta herramienta es para quienes no superan los $\$ 48.000$ de ingresos brutos anuales y, a través de ella, se brinda la posibilidad de ser proveedores del Estado, vinculándose así con la propuesta de la "compra pública/estatal". Esta propuesta fue incluida en la "Ley de Reparación Histórica de la AF", que otorga privilegios para que la AF sea proveedora de instituciones estatales (art. 22) ${ }^{11}$.

Por último, en la implementación a nivel local vemos que estas políticas no son solo de inclusión, sino que permiten al Estado y a los actores que buscan conservar su hegemonía, hacer uso de ciertos grados de coerción sobre los agricultores familiares. Es el caso del Monotributo Social Rural a través del cual se fuerza a los productores a incorporarse a programas, con características que son más propias de sectores agrícolas capitalizados que de la AF. Ello se ve aún más en las políticas de "agregado de valor en origen". Uno de los funcionarios provinciales sostuvo: "la propuesta ahi pasa por el valor agregado [...] integrarlos para poder poner una plantita de molienda, de hacer harina, para que después esa harina pueda venir a los barrios de la provincia" (Orlando, coordinador provincial de la SAF, Septiembre 2012). Para ello se crean infraestructuras como usinas lácteas, mataderos y/o frigoríficos municipales, salas de faena y con la asistencia productiva de programas como "Cambio Rural" y "Programas Sectoriales" (porcino, avícola, etc.) se incorpora a la $\mathrm{AF}$ a dichas cadenas de valor.

Este conjunto de iniciativas estatales tiene un impacto concreto a nivel local. Las condiciones materiales de existencia de los agricultores familiares, sus capaci-

8 Anexo VI de las actas de la III Reunión Especializada de Agricultura Familiar (REAF) sobre "Inserción de las especificidades de la agricultura familiar en la OMC". [Disponible en URL: <www.reafmercosul.org>. Consultado en septiembre de 2017].

9 Reunión Especializada de Agricultura Familiar (REAF): “Recomendación al GMC”. Diciembre 2014. [Disponible en URL: <www.reafmercosul.org>. Consultado en septiembre de 2017].

10 Anexo 8 de la XXI Reunión Especializada de Agricultura Familiar (REAF): "Declaración de Ministros sobre políticas públicas de abastecimiento y comercialización de productos de la Agricultura Familiar Campesina e Indígena". 27 de junio de 2014 [Disponible en URL: <www.reafmercosul.org>. Consultado en septiembre de 2017].

11 Honorable Congreso de la Nación Argentina (2014) "Ley de Reparación Histórica de la Agricultura Familiar para la construcción de una nueva ruralidad en la Argentina" (Ley No. 27.118). 
dades productivas y/o su inserción en el mercado pueden verse así, mejoradas. Ello tendría un efecto directo sobre sus capacidades económicas, sociales y políticas. Como contracara de esta situación, la dirección de los procesos a los cuales se incorporan los agricultores suele estar en manos de otros actores (del sector comercial, industrial y/o de funcionarios estatales), posibilitando nuevas formas de subordinación.

\section{Detrás de las políticas: territorialidades en pugna en Benito Juárez}

En el proceso por el cual una "cuestión socialmente problematizada" va consolidándose y emergiendo de él las políticas públicas, se pueden visualizar diferentes territorialidades, que en ocasiones se contraponen, y en otras se condensan en una territorialidad hegemónica, que envuelve a las subalternas. Sevilla Buitrago sostiene que "la territorialidad del bloque dominante [...] podrá aspirar, a su vez, a convertirse en una territorialidad hegemónica, pero para prevalecer ha de coexistir y luchar para prevalecer con otras territorialidades" (2014: 63). Una de las formas de garantizar eso es cuando la territorialidad que deviene hegemónica "envuelve las perspectivas de aquellos controlados y de aquellos que ejecutan el control" (Sack, 2013: 80). Así se refuerza la hegemonía a través de una relación dialéctica entre las fuerzas opuestas, pero donde es necesario "que, entre estas fuerzas, una asuma la función de "síntesis» superadora" (Gramsci, 1999: 234). Dentro de ésta, algunos elementos de cada fuerza se conservan en la nueva síntesis, lo cual "no puede ser determinado a priori, sino que resultará del proceso mismo" (Gramsci, 1999: 234).

Las territorialidades en pugna, así como la hegemónica se ven afectadas por las políticas públicas que se implementan en el área donde se lleva a cabo la disputa. Como afirma Cris Shore (2010: 36) ellas tienen un rol dominante al "regular y organizar las sociedades contemporáneas", ya que "construyen nuevas categorías de subjetividad y nuevos tipos de sujetos políticos". Ello modifica los criterios de "acceso diferencial" a recursos, a las personas (Sack, 2013) o al propio Estado. Es decir que modifican el territorio mismo y esto se hace visible en el caso estudiado. Pero para adentrarnos más en él, primero conoceremos algunos elementos que se refieren a las políticas para el sector que se desarrollan a nivel local.

Una de las características de Benito Juárez es que desde 1959 existe un programa que vincula la producción local con las necesidades alimentarias de la población juarense, y de las instituciones estatales: Abastos Municipales. Su principal función "era el expendio de artículos de primera necesidad, tales como: carne, leche, hortalizas, etc." (Ordenanza 199/1959). Según quien fuera concejal en ese momento, y luego Intendente (1963-1966 y 1983-1987), Aldo Mosse, se buscaba "proveer de alimentos de primera necesidad a las clases menos pudientes, [...] buscando la forma de poder vender carne barata. Subsidiada por el poco personal que tenía que le pagaba la municipalidad [...] Incorporamos también frutas y verduras" (Entrevista a Aldo Mosse, ex Intendente de Benito Juárez, año 2015).

Abastos Municipales no solo es un mecanismo de compra pública, para la venta a precios regulados, sino que también abastece a las instituciones estatales locales de los alimentos requeridos en su funcionamiento diario. Al momento de realizar esta investigación (2011-2015) solo abastecía de carne. Sin embargo, cuando se proveía de verduras, frutas y alimentos secos, también se entregaban a estas institu- 
ciones. Por lo tanto, esta iniciativa local ponía en marcha uno de los elementos de las políticas públicas que se proponen desde la REAF (la compra pública). Sin embargo, al indagar quiénes eran los beneficiados, pudimos dar cuenta que, mayormente eran realizadas a medianos productores ganaderos de la zona. A ello refieren varios entrevistados al decir que "les compran a los terratenientes" (Entrevista a Marta, Integrante de las Juntas Vecinales de Benito Juárez, año 2015) o como refirió otra informante que sostenía que "cuando pediamos los «documentos de transito animal» (DTA) veíamos que se le compraba a un productor importante, que por ahí está haciendo descarte" (Entrevista a Tania, Agente INTA, año 2015). Frente a esta situación algunos actores desde las instituciones vinculadas al sector desarrollaron acciones tendientes a vincular las producciones de la AF local con Abastos Municipales, lo cual fue intentado mediante la nueva institucionalidad que emerge como parte del proceso general de fortalecimiento e institucionalización del sector en el país.

Una de las primeras iniciativas que llevaron a cabo los "agentes de desarrollo" (de la SAF y de INTA) fue la constitución de un espacio de "cogestión" entre diferentes instituciones estatales: la Mesa de Desarrollo Local (MDL), que "se constituye como un espacio común para constituir un marco general para potenciar las acciones del sector público y privado tendientes a la promoción del desarrollo de la comunidad, bajo una óptica de planificación estratégica" (Mesa de Desarrollo Local, 2011). Esta estrategia de creación de consensos está completamente imbricada en las estrategias vigentes del DTR, que sostiene en su acta fundacional que su trabajo se realizará "entendiendo a su vez al territorio, no como un espacio físico o geográfico sino como una construcción social que expresa una identidad y un sentido de propósitos compartidos entre múltiples agentes públicos y privados"12.

Una de las primeras consecuencias de esta política fue la conformación de La Unión Juarense, una organización surgida de los procesos de asociativismo del programa "Cambio Rural" ". Con base en esa organización, se llevó a cabo un accionar destinado a volver a ampliar Abastos Municipales con las producciones de los agricultores familiares relevados, en especial con la producción de cerdos de esta organización. Uno de los productores comentó que "el problema que tiene son los precios y que no está bien [...] Nosotros no podemos discutir el precio. "Pagamos 8, listo», nos dicen" (Entrevista Fernando y José, Productores Familiares, año 2014). Sin embargo, los productores desarrollan otras acciones que buscan limitar algunos aspectos de dicha subordinación, ya que plantean "tener una reunión o hacer algo a ver si podemos pelear el precio [...] que paguen lo mismo que paga ahora el matarife" (Entrevista Fernando y José, Productores Familiares, año 2014).

Otra de las iniciativas surgidas de la MDL fue la constitución de una "Feria de la Economía Social y Solidaria" (FESS). Para ello, desde este espacio se busca conformar una organización de feriantes", combinando nuevamente consenso y coerción al impulsar "desde arriba" la organización social e intentando que tenga

Acta de constitución de la Mesa de Desarrollo Local de Benito Juárez. Septiembre de 2011.

El programa "Cambio Rural", nace en 1993 bajo el nombre de "Programa Federal de Reconversión Productiva para la PyME Agropecuaria". Se basa en generar procesos asociativos entre productores (de un mismo tipo) "a través de la contratación de un profesional que facilita la gestión integral de sus emprendimientos [...], acerca y brinda herramientas e instrumentos de financiamiento para promover procesos de innovación de los grupos". 
buscando autonomía para sostener "desde abajo" la FESS ${ }^{14}$. Fue esta propia organización, la que impulsó una ordenanza de "Promoción y desarrollo de la Economía Social y Solidaria (ESyS) de Benito Juárez".

En el texto de la ordenanza 4905/2014, aprobada en diciembre de 2014 quedan explicitados los límites y alcances de la "Promoción de la ESyS". Este proyecto busca, en sus mismas palabras, fortalecer un proceso de "desarrollo local y comunitario" impulsando un sector económico "que se sustenta en relaciones sociales equitativas y democráticas [...] generando nuevas relaciones económicas, sociales y culturales" (Ord. 4905/2014, art. 2). El punto que más nos importa en esta ordenanza es el nuevo rol que otorga a la ESyS en las compras públicas, dado que sostiene la necesidad de "promover la adecuación del régimen de compras del Estado municipal de forma tal que se garantice la adquisición de un mínimo de productos y servicios certificados como provenientes de la ESyS" (Ord. 4905/2014, art. 5, inc. 12$)^{15}$.

En cada una de estas iniciativas se registran diferentes posiciones por parte de los actores que intervienen en estas definiciones, cada una de ellas es reflejo de la defensa de sus propios intereses y por lo tanto de diferentes territorialidades. Así, por ejemplo, vemos que desde el sector comercial se sostiene la compra pública "perjudica al comercio que tiene que vender normalmente [...] por eso, se tendría que llegar un arreglo y ser privatizado. La municipalidad no tendría que manejar un comercio" (Entrevista a Alberto, Presidente del Centro de Propietarios de Carnicerías de B. Juárez, año 2015). De la forma en que estas acciones y territorialidades se procesen en el seno del Estado local y de la cristalización que surja como como resultado de dicho proceso, dependerá como se vaya conformando el territorio en cuestión.

$\mathrm{Si}$ analizamos como se despliegan esas territorialidades dentro de esta institucionalidad, podemos ver cómo se transforma el territorio en cuestión. La creación de la FESS es producto de una acción estatal destinada a integrar socialmente en ella a los actores subalternos, ello modifica las relaciones de fuerza a nivel local. Si bien aquí los actores englobados en la "economía social" son integrados de manera subordinada - políticamente conducidos por los "agentes de desarrollo"-, llevan a cabo una apropiación simbólica y material del espacio donde su actividad se emplaza (espacios de relevancia histórica y geográfica). Desarrollan en ellos una territorialidad que se involucra más en "nuestras relaciones cotidianas en tramas, [...] en la calle, en la plaza, [...] en la ciudad-urbana, en el rural-agrario" (Saquet, 2015: 86). El fortalecimiento de esta territorialidad de los agricultores familiares y de la economía social luego se plasmó en la sanción de una ordenanza de "Promoción y desarrollo de la Economía Social y Solidaria (ESyS) de Benito Juárez" (Ord. N ${ }^{\circ}$ 4905/2014). Esta transformación en las relaciones de poder se condensa en cambios institucionales, normativos, legales, que amplían los "niveles de acceso", a decir de Sack, a los recursos del Estado por parte de todos aquellos actores involucra-

14 Según el reglamento "la FESS conformará una Organización de Feriantes, compuesta por 6 representantes de los tres grandes rubros de la Feria (artesanías-manualidades, verdes y alimentos). Esta organización estará acompañada por un representante del Municipio, un representante del INTA y un representante de la SAF" Reglamento Interno, Libro de Actas de la Feria de la Economía Social y Solidaria de Benito Juárez. Benito Juárez, 2011.

15 Honorable Concejo Deliberante de Benito Juárez (2014). Ordenanza 4905/2014. Promoción de la Economía Social y Solidaria. 
dos en actividades de la economía social — incluyendo a la AF-. Es decir, la territorialidad subalterna extiende aquí sus límites de influencia hacia áreas donde anteriormente no llegaba (por ejemplo, la posibilidad de ser proveedor del Estado).

La puesta en marcha de procesos de cogestión interinstitucional para implementar políticas a nivel local, también manifiesta transformaciones en el territorio. En la información recogida pudimos constatar 21 municipios donde se han instalado los "espacios de cogestión". En el partido de Benito Juárez fue la Mesa de Desarrollo Local, que por medio de políticas de inclusión social como el Monotributo Social - y su necesaria inclusión en el ReNAF-, la que conformó La Unión Juarense. Sin embargo, esto no ha modificado la posición de la AF a nivel local, ya que ese grupo de productores, para existir como tal dependía de los recursos del Estado $\mathrm{y}$ de las agencias que promovieron esa acción (INTA-SAF). Esto no niega cierto fortalecimiento del sector, ya que este mismo grupo se ha convertido en proveedor ocasional del Abasto Municipal, y ante los intentos de subordinación (como la negación de posibilidad de discutir los precios de la compra pública) han manifestado voluntad de reclamar y defender sus derechos y posicionamientos.

Estos aspectos a los que nos hemos referido, nos llevan a la conclusión de que los actores subalternos - en especial los agricultores familiares - han sido incluidos dentro de una territorialidad hegemónica, que envolvía su acción, incorporando algunas de sus demandas, pero dirigiéndolas en el sentido que promueven los grupos dominantes. Esto queda manifestado en ciertas concepciones que los agricultores familiares sostienen como si las "hubieran adoptado por sí mismos y como máxima de su propio obrar", como diría Weber. Estas ideas son transmitidas por los "intelectuales orgánicos", que poseen legitimidad por "determinados conocimientos técnicos en alguna otra área próxima a la producción económica" (Gramsci, 1970: 5). Una productora hortícola de Benito Juárez, nos informó que compraba "las semillas importadas porque son semillas seguras. [...] Nunca nacional ni... nada [...] Te puede fallar todo el lote" (Entrevista a Flavia, Productora Hortícola Familiar de Benito Juárez, año 2014). Cuando fue consultada sobre quien le hizo esa recomendación afirmó que fue el "Ingeniero". En muchos casos ello hace que el "rol" que los productores se autoadjudican está vinculado a la territorialidad y al imaginario de desarrollo que estos técnicos promueven. Esta familia productora, deja su venta a nivel local para llevar al mercado concentrador de Mar del Plata, donde ejercen su influencia estos "centros de poder" que son las grandes semilleras. Otro productor, miembro de La Unión Juarense, sostuvo que el principal problema de su sector es que se cierran las exportaciones, aun cuando por su actividad no accede a esa posibilidad ${ }^{16}$.

Creemos que la conformación del territorio producto de las políticas de desarrollo rural en Argentina y en particular en la Provincia de Buenos Aires, tienen las características de una "revolución pasiva", que combina elementos de transformación, con otros de restauración. De esta manera podemos ver cómo se conforma la

16 Uno de los productores porcinos que participa de "La Unión Juarense" sostuvo que "ya nos ha pasado [...] como pasó con la vaca en el 2007, 2008 que las vacas se regalaban. Y pasó con el trigo el año pasado. El año pasado no se sembró trigo prácticamente porque se cerraron las exportaciones" (Entrevista a Fernando y José, productores y miembros de "La Unión Juarense", año 2014). Casualmente es el mismo discurso que sostiene los productores empresariales a nivel local que manifestaron que "el trigo se deja de hacer porque no es redituable por el precio de venta que vos tenés. ¿Por qué se da ese precio de venta? Porque se cierra la exportación de trigo" (Entrevista a Directivos de la Asociación de Productores de Benito Juárez, año 2014). 
territorialidad que deviene hegemónica y, por lo tanto, cómo se construye el territorio. Entonces, para concluir nos preguntamos: ¿qué elementos subalternos se incluyen en la territorialidad hegemónica?, ¿existen iniciativas con vocación contrahegemónica en las territorialidades subalternas a nivel local? Acercarnos a estas preguntas es necesario para construir una geografía que analice de manera relacional el poder y, por lo tanto, el territorio.

\section{Reflexiones finales}

Para una primera reflexión podemos comenzar visualizando los elementos de las territorialidades subalternas que son incorporados dentro de la territorialidad hegemónica. Creemos que el ejemplo más claro de ello son las acciones vinculadas a la economía social. Ellas, son un elemento surgido dentro del repertorio de acciones subalternas, en el que los intercambios comerciales tienen otros valores, diferentes a la "economía de mercado". Al ser incorporado dentro de las políticas públicas para la AF, tanto en el caso analizado (Benito Juárez), como a nivel nacional la demanda subalterna de establecer espacios para la comercialización de la AF, cambia su carácter. Pasa de ser "otra economía", a ser un elemento de inclusión más en la economía convencional. No coloca a la AF en el rol de garantizar seguridad y/o soberanía alimentaria, sino que sólo busca incluirla socialmente, negando su potencialidad de actor económico y político (con capacidad de decisión autónoma). Esto refuerza la subalternidad del sector.

Otro elemento a analizar, son las políticas de "agregado de valor", en las que los productores familiares son simplemente un elemento más en la cadena de valor, a la que es necesario integrarse. En ello se basan las políticas de "agregado de valor en origen", no en el rol (supuestamente otorgado) de ser la garantía de seguridad y/o soberanía alimentaria, lo cual valorizaría políticamente al sector. Ambas demandas son transformadas de acorde a las necesidades y voluntades de quienes comandan ese proceso político, y no de quienes lo resisten.

Por otro lado, analizar la posibilidad de que en estos territorios se dé lugar a territorialidades contrahegemónicas requiere analizar la capacidad de los actores subalternos de reconocer los elementos (que estando en gestación a partir de la subalternidad) pueden fortalecer su posición en las relaciones de fuerza a nivel local. Para ello, dichos actores necesitarán reconocer aliados (como lo han hecho en torno a la economía social) y otras variables en juego. Pero esto debe resguardar la dirección ideológica de los actores subalternos para quienes representen sus propios intereses. Considerando que el territorio es también articulaciones sociales, cooperaciones, cohesiones (Saquet, 2015) y no solamente conflicto, esta dimensión debe estar presente en el análisis de las territorialidades contrahegemónicas por venir.

En este sentido, vemos que las transformaciones territoriales tienen más elementos de preservación que de transformación, de inclusión subordinada que de potencialidades emancipadoras. No obstante, creemos que también es válida una mirada alternativa a la que proponemos, y que sostiene que la creación "desde arriba" del sujeto político de la AF puede dar lugar a cambios sociales "desde abajo". Si bien es esta una posibilidad, las probabilidades de que estos cambios ocurran son bajas en nuestro estudio de caso. Eso es mayormente probable en casos donde la 
organización de los sectores subalternos conserve su autonomía, pero se proponga ir más allá de los límites de su propia territorialidad, generando transformaciones territoriales que, bajo su control, hagan visibles una nueva síntesis de las territorialidades existentes.

\section{Bibliografía}

Balsa, Javier (2006) "Las tres lógicas de la construcción de hegemonía”. Revista Theomai, núm. 14, 16-36.

Bobbio, Norberto (1985) Estado, gobierno y sociedad: por una teoría general de la politica. México D. F.: Fondo de Cultura Económica.

Duso, Giuseppe (coord.) (2005 [1999]). El poder. Para una historia de la filosofía moderna. México D. F.: Siglo XXI.

Failde, A.; Mondelli, M., \& Peixoto, C. (2011) "Inserción de la Agricultura Familiar en los Modelos de Gobernanza De las cadenas agroindustriales: casos en Uruguay y Paraguay”. FAO [Puesto en línea en agosto de 2011. URL: <http://www.fao.org/3/aas409s.pdf $>$. Consultado en diciembre de 2015].

FAO/CEPAL/IICA (2013) "Perspectivas de la agricultura y del desarrollo rural en las Américas: una mirada hacia América Latina y el Caribe: 2014”. FAO [Puesto en línea en marzo de 2013. URL: <http://www.fao.org/docrep/019/i3702s/i3702s.pdf >. Consultado en diciembre de 2015].

González, Fernando (2016) "La Agricultura Familiar en Argentina: entre el consenso, la coerción, la inclusión y la subordinación”. Redes, vol. 21, núm. 3, 75-96.

Gordillo, Gastón (2006) En el Gran Chaco. Antropologías e historias. Buenos Aires: Edit. Prometeo.

Gramsci, Antonio (1970) Los intelectuales y la organización de la cultura. México D. F.: Juan Pablos Editor.

Gramsci, Antonio (1980) Notas sobre Maquiavelo, sobre la política y sobre el Estado moderno. Madrid-Buenos Aires: Ediciones Nueva Visión.

Gramsci, Antonio (1999) Cuadernos de la Cárcel. Edición crítica del Instituto Gramsci. México D. F.: Ediciones Era, t. 5.

Haesbaert, Rogerio (2006) O mito da desterritorializaçao: do "fim dos territórios" à multiterritorialidade. Río de Janeiro: Bertrand Brasil.

Haesbaert, Rogerio (2010) Regional-Global, Dilemas da Região e da Regionalização na Geografia Contemporânea. Rio de Janeiro: Bertrand Brasil.

Lattuada, Mario; Nogueira, María Elena \& Urcola, Marcos (2015) Tres décadas de desarrollo rural en la Argentina: continuidades y rupturas de intervenciones públicas en contextos cambiantes 1984-2014. Buenos Aires: Editorial Teseo - Universidad Abierta Interamericana.

Lefebvre, Henri (2013 [1974]) La producción del espacio. México D. F.: Siglo XXI.

Manzanal, Mabel (2007) "Territorio, Poder e Instituciones. Una perspectiva crítica sobre la producción del territorio", en M. Manzanal, M. Arzeno \& B. Nussbaumer (comp.) Territorios en construcción. Actores, tramas y gobiernos, entre la cooperación y el conflicto. Buenos Aires: Ed. CICCUS, 7-35.

Manzanal, Mabel \& González, Fernando (2010) "Soberanía Alimentaria y Agricultura Familiar. Oportunidades y desafíos del caso argentino". Realidad Económica, núm. 255, $12-42$. 
MNCI (2009) “Algunas verdades sobre el FoNAF”. [Puesto en línea el 12 de agosto de 2009. URL: <www.mocase.org.ar/2009/08/algunas-verdades-sobre-el-fonaf.html>. Consultado en septiembre del 2010].

Modonesi, M. (2012) "Revoluciones pasivas en América Latina. Una aproximación gramsciana a la caracterización de los gobiernos progresistas de inicio del siglo", en M. Thwaites Rey (ed.) El Estado en América Latina: continuidades y rupturas. Santiago de Chile: CLACSO/ARCIS, 139-166.

Oszlak, Oscar (1982) "Reflexiones sobre la formación del Estado y la construcción de la sociedad argentina”. Desarrollo Económico, vol. 21, núm. 84, 531-548.

Oszlak, Oscar \& O’Donell, Guillermo (1995) "Estado y políticas estatales en América Latina: hacia una estrategia de investigación”. Redes, vol. 2, núm. 4, 99-128.

Paz, Raúl \& Jara, Cristian (2014) “Censos y registros de la agricultura familiar en Argentina: esfuerzos para su cuantificación”. EUTOPIA Revista de Desarrollo Territorial, núm. 6, 75-91.

Peet, Richard (2007) "Imaginarios de Desenvolvimento", en B. M. Fernandes, M. I. M. Marques \& J. C. Suzuki (orgs.) Geografia Agrária: teoria e poder. São Paulo: Expressão Popular, 19-37.

Portelli, Hugues (1977) Gramsci y el Bloque Histórico. México D. F.: Siglo XXI.

Portes, Alejandro (2006) "Instituciones y desarrollo: una revisión conceptual". Desarrollo Económico, núm. 184, 475-503.

Raffestin, Claude (1993 [1980]) Por uma geografia do poder. São Paulo: Editora Ática.

Ramírez Miranda, C. A. (2011) "Crítica al establishment del desarrollo en el campo: nueva ruralidad y desarrollo territorial rural”. Estudios Latinoamericanos, núm. 27-28, 107 128.

Sack, Robert (1986) Human territoriality: its theory and history. Cambridge: Cambridge University.

Sack, Robert (2013) "O significado de territorialidade”, en L.C, Dias y M. Ferarri (eds.) Territorialidades Humanas e Redes Sociais. Santa Catarina: Editora Insular, 63-89.

Saquet, Marco Aurelio (2007) "As diferentes abordagens do território e a apreensão do movimento e da (i)materialidade". Geosul, vol. 22, núm. 43, 55-76.

Saquet, Marco Aurelio (2015) "Por uma abordagem territorial", en M. A. Saquet y E. S. Sposito (orgs.) Territórios e territorialidades. Teorias, procesos e conflitos. Rio de Janeiro: Consequencia Editora, 69-90.

Schejtman, Alexander \& Berdegué, Julio (2004) "Desarrollo Territorial Rural". Santiago de Chile: RIMISP- Centro Latinoamericano para el Desarrollo Rural. [Puesto en línea en marzo de 2004. URL: <http://www.rimisp.org/wpcontent/files_mf/1363093392schejtman_y_berdegue2004_desarrollo_territorial_rural_5_ri misp_CArdumen.pdf $>$. Consultado en noviembre de 2012].

Schiavoni, Gabriela (2012) "Objetivación y medida: el registro de la agricultura familiar en Misiones”, en M. Manzanal y M. Ponce (orgs.) La desigualdad ¿del desarrollo? Controversias y disyuntivas de desarrollo rural en el norte argentino. Buenos Aires: Ed. CICCUS, 51-68.

Sevilla Buitrago, Álvaro (2014) "Hegemonía, gubernamentalidad, territorio. Apuntes metodológicos para una historia social de la planificación". EMPIRIA. Revista de Metodología de Ciencias Sociales, núm. 27, 49-72.

Shore, Cris (2010) "La antropología y el estudio de la política pública: Reflexiones sobre la ‘formulación' de las políticas”. Antípoda, núm.10, 21-49. 
Sosa Velázquez, Mario (2012) ¿Cómo entender el territorio? Guatemala: Ed. Cara Parens. Thwaites Rey, Mabel (1994) 'La noción gramsciana de 'Hegemonía' en el convulsionado fin de siglo. Acerca de las bases materiales del consenso", en L. Ferreyra, E. Logiudice \& M. Thwaites Rey (1994) Gramsci mirando al Sur. Sobre la hegemonía en los 90. Buenos Aires: K\&Ai-Kohen Ediciones, 15-84.

Thwaites Rey, Mabel (comp.) (2007) Estado y marxismo: un siglo y medio de debates. Buenos Aires: Editorial Prometeo.

Weber, Max (2002 [1922]) Economía y Sociedad. Esbozo de sociología comprensiva. Madrid: Fondo de Cultura Económica. 